\title{
Spatial Representation Framework for Better Indoor Navigation by People with Visual Impairment
}

\author{
Watthanasak Jeamwatthanachai, Mike Wald, Gary Wills \\ School of Electronics and Computer Science \\ University of Southampton, Southampton, UK \\ \{wj1g14, mw, gbw $\} @$ ecs.soton.ac.uk
}

30th December 2018

\begin{abstract}
Purpose - The research aims to find an appropriate framework for spatial representation, aka Spatial Representation Framework (SRF), to define spaces and buildings targeted at indoor navigation by people with visual impairment.

Design/methodology/approach - The SRF was first created with initially 7 main components by a review of the relevant literature and state-of-the-art technologies shown in the preliminary study. A field study was then conducted to validate and ensure that the SRF meets the needs of people with visual impairment and is deployable in a real situation. This study comprised two tasks: (i) investigating indoor navigation problems and (ii) validating of SRF which 45 participants were recruited with 30 visually impaired people and 15 sighted people.

Findings - While designing the framework, a list of problems and challenges were discovered and were used to refine and finalize the spatial representation, which was validated by both visually impaired and sighted people. The framework consists of eleven components categorized into five layers, each layer of which is responsible for a different function.

Practical implications - Many applications can be extended to provide a range of indoorbased applications by using this spatial representation framework to represent indoor spaces. Example applications are: indoor navigation by people with disabilities, robots and autonomous systems, security and surveillance, and context and spatial awareness.

Originality/value - This article presents a design architecture of BRS with its details, description and Success Criteria used in the space classification.
\end{abstract}

\section{Introduction}

In 2014, the World Health Organization [1] estimated the number of visually impaired people at 285 million worldwide, of which 39 million are blind, and 246 million have low vision. Lack of vision creates difficulties directly affecting most activities, especially those requiring ability to navigate. Being unable to obtain information about where they are or where to go in public buildings such as colleges/universities, malls, hospitals, public transportations, and airports causes problems in their wayfinding process discouraging them to go out themselves. The study [2] found 80-90\% of visually impaired people spent their life inside buildings.

People with visual impairment encounter many problems and challenges such as obstacles, noise, and other barriers, which directly affect their ability to navigate a space. Zeng presents nine important barriers to visually impaired people while traveling outdoors: for example, a lack of accessibility information provided [3], such as audible information when crossing the street or using public transportation [4], a non-standard length of sidewalk and stairs [5] , warning information while walking through a construction (hazard) area, roadside and by 
cliffs. Moreover, the study also identified moveable objects (car, people and mobile home), and unpredictable weather (rain and snow) are unexpected obstacles. These findings show that the main barriers are a lack of warning, lack of attention by the guide dog, unexpected obstacles, and wrongful measurement of distance and angle.

Walking inside buildings and public spaces seems to create other difficulties since visually impaired people cannot sense and use landmarks, also known as navigational cues, to help them move around the spaces. Especially, walking through unfamiliar, crowded, and wide-open spaces due to limitation of their sensing environment cues (light, smell, and noise) [6], where head-level and trip accidents and even movable objects are still taken into consideration. Apparently, it is hard to decide which way to reach the destination in such complex and crowded environments [7]. Consequently, visually impaired people take a long time to familiarize themselves with spaces and to construct a mental map [8], in a similar way to a guide dog that needs to be trained beforehand to make it familiar with the environment and to let it remember a standard or appropriate route [9]. Although the guide dog is a reasonable choice to accompany them, it is not permitted in some buildings by specific regulations e.g., hospitals [10] and theaters [11].

Thanks to the advance in technology that enables visually impaired people to engage with their lives, providing facilities to make them capable of accessing information e.g., text-tospeech and screen reader. One particular example that adopted the features is BlindSquare, a mobile application provides the accessibility information such as points of interest, street, and intersection to the user through audible feedback [12]. However, the accuracy of estimating location inside buildings is still difficult, due to the limitation of GPS, as walking with misjudgment of distance could cause trip accidents [13]. Consequently, an indoor positioning system (IPS) was invented using various sensor technologies, providing the user with a facility to find locations inside buildings. However, such systems [7, 14, 15] and commercial products (e.g. Indoor.rs and Wifarer) usually provide integrated maps displayed as a general map providing information about the internal layout of the buildings used in a route-finding process.

However, for visually impaired people (and even robotics and autonomous systems), general maps would not be enough to help navigate inside a building since extra information [16, 17] is needed, such as landmarks, obstacles, hazards, etc. This information is paramount to provide free mobility used to promote indoor navigation capability such as the presence of objects, obstacles, transitions, and accessibility information. Nonetheless, for visually impaired people, maps are widely used in appropriate formats, such as tactile maps and accessible maps, which enable them to learn the environment beforehand, develop the familiarity of spaces and mental maps [18, 19, 20], and helps them prepare for the experience as pre-visit information. As a result, the map has played in a significant role in improving and accelerating the process of constructing the mental map [21].

The aim of this study is to propose a Spatial Representation Framework (SRF) that can solve some of these problems. To design the indoor maps that is appropriate for visually impaired people, a spatial representation framework for indoor navigation is proposed. The framework is based on the results and discussion from the field study regarding essential behaviors, strategies used, and challenges experienced by people with visual impairment. The framework was first developed [22] using IndoorGML [23] as a skeleton. The framework was validated and improved, using the findings from a field study, and consists of five layers (split into eleven components) which represent the buildings and information for visually impaired people. This representation is designed for visually impaired people to have the freedom to navigate inside unfamiliar buildings. 


\section{Methodology}

This section describes the steps used to develop the SRF for indoor navigation by people with visual impairment. The SRF was originally created by a review of the relevant literature and state-of-the-art technologies. The problems discovered in the literature are: behavior, navigation strategies, wayfinding, obstacle detection and avoidance. This process resulted in 7 main components: structural, fixed objects, rearrangeable objects, transient objects, sensor, path, and information. Details on the preliminary study can be found in [22].

A field study was then conducted to ensure that the SRF meets the needs of people who are blind and is deployable in a real situation. This study comprised two tasks: (i) investigating indoor navigation problems, (ii) validating of SRF. Nonetheless, the purpose of this article is to formulate the finalized version of the SRF, which can be used to construct the indoor map, based on actual behaviors, strategies used and challenges experienced by visually impaired people when walking inside buildings and public spaces full of unfamiliar features. Therefore, information and feedback from visually impaired people is important to our study. However, the environment perception of visually impaired people varies, depending on personal characteristics [20] such as age, cognitive development, type of blindness (congenital or adventitious), and level of blindness. In this study, 45 participants were recruited with 30 visually impaired people and 15 sighted people.

Ten visually impaired people were from the United Kingdom, and 20 from Thailand randomly chosen with evenly distributed numbers of males and females. 10 participants selfreported as congenitally blind, whereas 20 participants were adventitious blind. 22 participants self-reported as severely sight impaired (blind), while 8 participants were sight impaired (partially sighted). The sighted participants were (i) chaperones and orientation and mobility (O\&M) instructors, and (ii) developers and researchers in technical fields: human-computer interaction, accessibility, assistive technology, and interior design for elderly and disabled people.

Both groups were asked to give an interview individually, where all questions were split into three sections, regarding indoor navigation by people with visual impairment, consisting of (i) demographic information, (ii) indoor navigation problems and (iii) a framework validation. The results from both groups were used in terms of complementarity, clarity, and elaboration of the findings, towards the refinement of the SRF.

\section{Spatial Representation Framework}

This section describes the spatial representation framework (SRF) for indoor navigation by people with visual impairment that was developed from the review of literature and the study of indoor navigation behavior. It is intended to help visually impaired people have freedom and confidence when navigating inside buildings and public spaces on their own. It provides a skeleton of essential information needed in order to build maps for indoor navigation systems for visually impaired people, and in the future autonomous systems and robots. In Section 5.1, main and sub-components of the framework are described with examples of information stored in each component. Section 5.2 shows the reference model used to define the component levels for the construction of indoor-based applications. The framework's components are later discussed with definitions and examples provided, especially the objects classification component in Section 5.3.

\subsection{SRF Components}

This research aims to provide basic principles that can be used to promote indoor navigation by people with visual impairment, and used as a skeleton for further development, especially maps for indoor-based applications and systems such as: indoor navigation for people with disabilities, 
and in the future autonomous systems and robots. Figure 1 presents the final version of the SRF with details of each component. The framework has eleven components, eight of which are grouped as a reference model (shown in Section 3.2) and describe the buildings, two components are placed beside the multiple-layered model and act as metadata, while the last component is external information, e.g. weather and noise from outside the buildings.

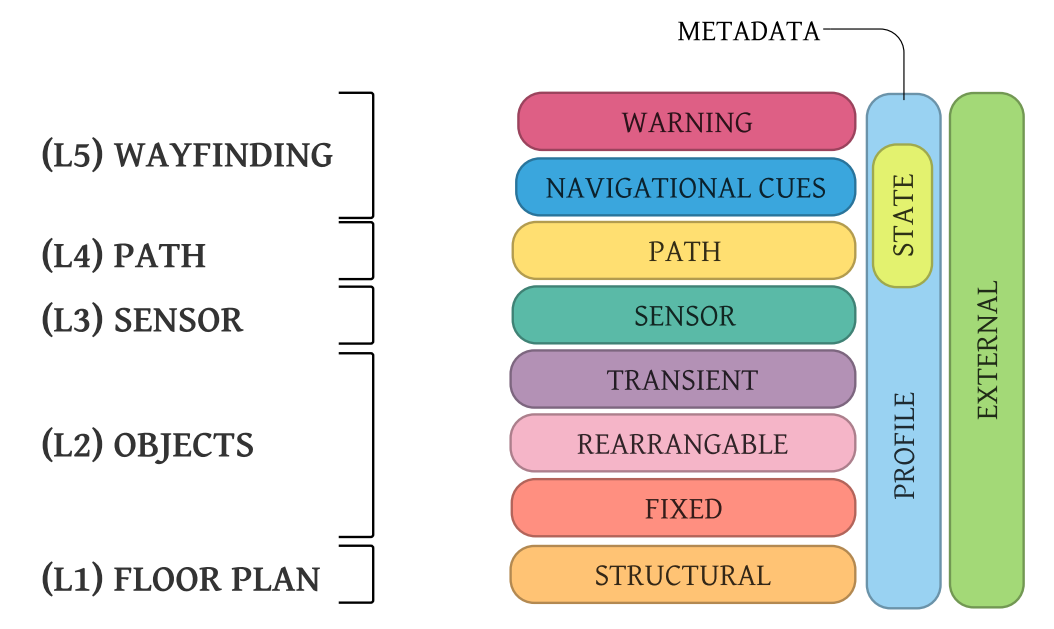

Figure 1: Spatial Representation Framework for Indoor Navigation by People with Visual Impairment structured in the form of 5-levels reference model.

Each of the layers represents a different purpose and are defined below.

1. Structural: The bottommost layer represents the floor layout showing relation- ships between rooms and transition spaces (e.g. doors) for each floor inside the building, where each floor can be linked to another floor by the transition spaces (e.g. stairs, escalators, and lifts) in order to form the buildings in 3D. This also includes information about physical dimension, size, wall type, floor type, etc. This layer is compulsory as it provides information about the structure of the building.

2. Fixed Objects: This component contains information about fixed objects permanently installed inside the buildings e.g. fixed furniture and transition objects like doors, stairs, escalators, and lifts. This component also encompasses barriers that impact indoor navigation, such as drop-offs, curbs, events, and restricted areas (e.g. construction and renovation areas). This component provides information regarding landmarks, which is useful for navigation inside buildings full of unfamiliar configurations. A scaling method will be provided to classify the objects, examples of which are in Section 3.3.

3. Rearrangeable Objects: This component contains information about objects that can be rearranged like furniture (e.g. table, chairs, waste bins) or other objects that remain in their position for a medium to long period of time, depending on a movability factor scaled in Figure 4. This component provides information about random objects, which are navigation barriers and thus obstacles. A scaling method will be provided to classify the objects, examples of which are in Section 3.3.

4. Transient Objects: This component contains information about objects that can be rearranged, but last for a short period of time, e.g. self-moving objects like people, pets, autonomous systems, and robots. This component provides information about random objects that are navigation barriers and obstacles. This component is used to measure indoor traffic, detect objects, find an appropriate route. A scaling method will be provided to classify the objects, examples of which are in Section 3.3. 
5. Sensor: A special object that possesses the ability to detect events and send out information to the spaces for specific purposes, e.g. lighting, smoke detector, Wi- Fi, RFID, closed-circuit television (CCTV), camera, door switch sensor. This component contains information on sensors installed within the buildings. This component is useful for many applications and extensions beside visually impaired navigation such as indoor localization and navigation, obstacle detection, and security and surveillance.

6. Path: A component that contains information about the walkable area (e.g. hall- ways) and restricted area (e.g. Emergency Exit), enabling people with visual impairment to know which area and path are approved for walking. This component can be used as part of the route planning process for indoor navigation systems, and construction of accessible maps.

7. Navigational cues: This component contains markers and information about the objects (e.g. edges and corners), areas (e.g. intersection), especially transition spaces e.g. stairs: stair width, tread width, riser height, and depth width. This information can be used as a navigational cue to help find the way more easily in a building full of unfamiliar configurations.

8. Warning: This component contains warning markers and information about hazards, e.g. sharp edges, stairs and escalators, slippery surfaces, holes, drop-offs, and especially glass doors and automatic sliding doors. This component enables free mobility.

9. Profile: A metadata component that contains a description of the areas and objects placed or installed inside buildings, including physical dimensions, sizes, wall type, etc. This component also includes general information about the building, e.g. building profile, pre-visit information.

10. State: A sub-component of the Profile that contains information about the current state of the objects, especially transition spaces, e.g. doors, elevators, escalators, and travellators, e.g. door (open, closed), escalator (going up, going down), or lift (going up, going down, current floor).

11. External: A component that contains sensory information that potentially impacts indoor navigation. such as light through windows, noise from rain, car horn, or outside construction sounds. This component is useful to people with visual impairment, especially those who are partially sighted and use light to detect orientation in the wayfinding process.

\subsection{Spatial Representation Model}

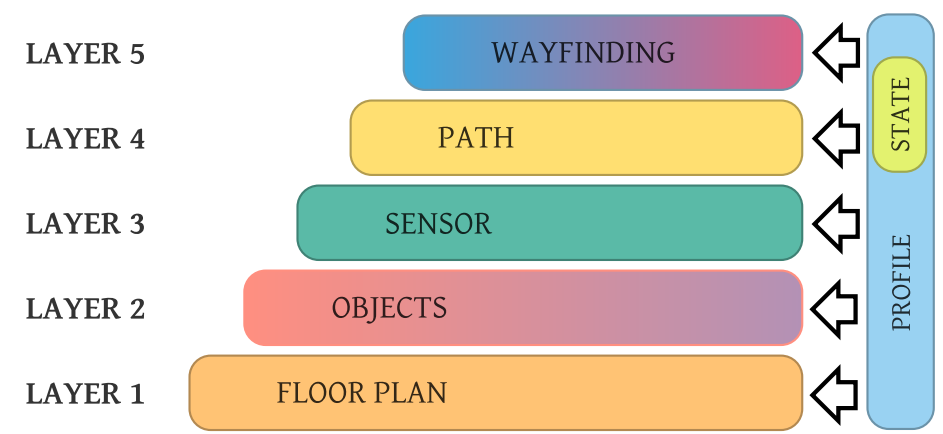

Figure 2: Spatial Representation Model by a use of Reference model 
From the conceptual framework, shown in Figure 1, and the definition of components, the framework is arranged as a reference model, also known as the Spatial Representation Model (SRM), in which indoor spatial information is represented by a collection of data and relationships mapping between layers, as shown in Figure 2. To visualize the buildings in 3D, the spatial representation is designed by first creating the floor plan layer (level 1). The objects layer combines components to become the second layer (level 2), which represents the information about the objects installed and placed in the building. The sensor layer was originally designed for indoor positioning systems, but it also provides information about lighting for people who have light perception, and other purposes such as cameras for obstacle detection. The path layer (level 4) provides information about walkable areas and paths, while the wayfinding layer (level 5) provides free mobility and warning information about hazards.

Table 1: Bottom-up design of the SRM and its potential applications

\begin{tabular}{|l|l|l|}
\hline Level & Description & Potential Applications \\
\hline $\begin{array}{l}\text { L5: } \\
\text { Wayfinding }\end{array}$ & $\begin{array}{l}\text { Navigational cues and } \\
\text { warning information }\end{array}$ & $\begin{array}{l}\text { Indoor navigation system for people with disabilities, } \\
\text { Interactive accessible map }\end{array}$ \\
\hline $\begin{array}{l}\text { L4: } \\
\text { Path }\end{array}$ & $\begin{array}{l}\text { Walkable areas and } \\
\text { paths }\end{array}$ & $\begin{array}{l}\text { Indoor navigation system for autonomous } \\
\text { systems and robots, Indoor route planning }\end{array}$ \\
\hline $\begin{array}{l}\text { L3: } \\
\text { Sensor }\end{array}$ & $\begin{array}{l}\text { Camera, Wi-Fi, RFID, } \\
\text { others }\end{array}$ & $\begin{array}{l}\text { Indoor positioning system, Obstacle } \\
\text { detection and avoidance, Security and } \\
\text { surveillance system, Access control system }\end{array}$ \\
\hline $\begin{array}{l}\text { L2: } \\
\text { Objects }\end{array}$ & $\begin{array}{l}\text { Fixed, rearrangeable, } \\
\text { and transient objects }\end{array}$ & $\begin{array}{l}\text { Floor plan with interior, Spatial } \\
\text { awareness, Accessible map }\end{array}$ \\
\hline $\begin{array}{l}\text { L1: } \\
\text { Structural }\end{array}$ & $\begin{array}{l}\text { Relationships between } \\
\text { rooms, spaces, entrances }\end{array}$ & $\begin{array}{l}\text { Floor plan, General indoor } \\
\text { map }\end{array}$ \\
\hline
\end{tabular}

With all these information, Table 1 shows how each layer comes into play with the others to support development. The lowest layer (L1) may be used to construct the floor plan of all floors in the building as the general indoor map. Including objects (L2), the floor plan now has interior information which can increase spatial awareness for people with visual impairment. Enhanced with sensor information (L3), applications can be extended, e.g. Camera: obstacle detection and avoidance, and Wi-Fi: indoor positioning and navigation systems. In the path layer (L4), information about the walkable area and paths satisfies the indoor navigation systems, and informs people with visual impairment which areas are approved for walking. Finally, including the wayfinding layer (L5), enables maps to be of use for people with disabilities, providing free mobility information.

\subsection{Objects Classification}

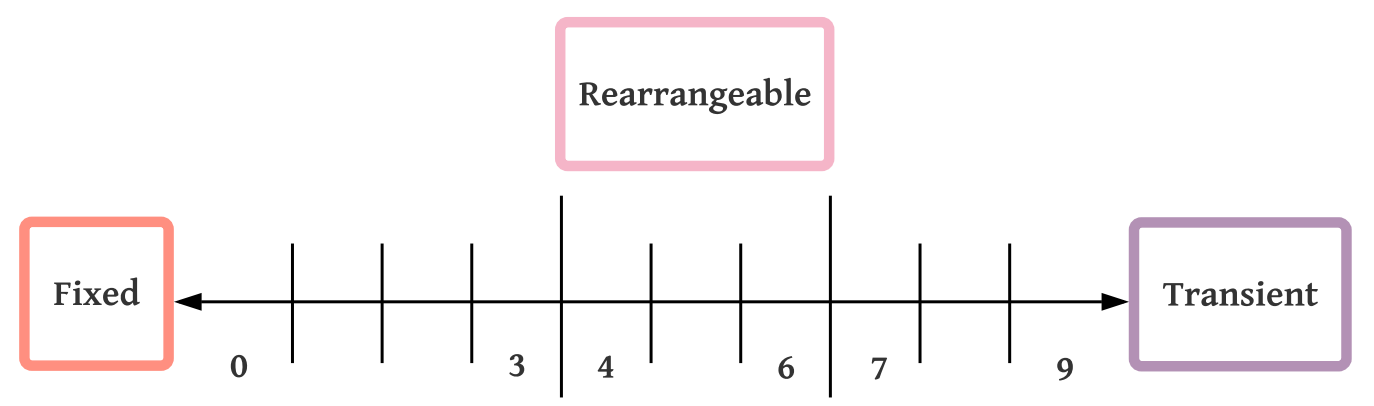

Figure 3: SRF - Objects classification 
To classify the objects into three types: fixed, rearrangeable, and transient, a movability factor is used factor scaled in a range from 0 (fixed) to 9 (transient), shown in Table 4 . The definitions of each type of object are given below, based on this scaling.

- Fixed Objects: Predictable objects installed or attached inside the building at any height (ground, body, or head level) for a long period of time, or permanently, such as floor-mounted furniture, wall-mounted furniture, stairs, escalators, travellators, lifts, and railings.

- Rearrangeable Objects : Random objects placed inside the building that can be rearranged, or remain in their position for a medium to long period of time. For example, furniture, electric appliances, portable things.

- Transient Objects: Random objects that remain in their position for a short period of time, and usually have self-moving ability, e.g. people, crowds, robots, autonomous systems, and robots.

Table 2: Classification of Objects: Scaling Definitions and examples

\begin{tabular}{|c|c|c|c|}
\hline Types & Scale & Definitions & Examples \\
\hline \multirow[t]{4}{*}{ Fixed Objects } & 0 & $\begin{array}{l}\text { Permanently part of the building, } \\
\text { cannot be changed }\end{array}$ & $\begin{array}{l}\text { Stair, Sidewalk, Pavement } \\
\text { Drop-off, Sloped floor, Kerb, Hole } \\
\text { in the ground }\end{array}$ \\
\hline & 1 & $\begin{array}{l}\text { Installed in the building, } \\
\text { impossible or hard to uninstall }\end{array}$ & $\begin{array}{l}\text { Elevator, Escalator, Travelator, } \\
\text { Fence }\end{array}$ \\
\hline & 2 & $\begin{array}{l}\text { Installed in the building, can be } \\
\text { removable }\end{array}$ & $\begin{array}{l}\text { Floor-mounted furniture, } \\
\text { Wall-mounted furniture, Built-in } \\
\text { furniture, Bathroom equipment } \\
\text { (basin, shower bowl, toilet, urinal) }\end{array}$ \\
\hline & 3 & $\begin{array}{l}\text { Temporarily installed in the } \\
\text { building, with time limit }\end{array}$ & $\begin{array}{l}\text { Construction area, Building } \\
\text { renovation, Events }\end{array}$ \\
\hline \multirow[t]{3}{*}{$\begin{array}{l}\text { Rearrangeable } \\
\text { Objects }\end{array}$} & 4 & $\begin{array}{l}\text { Large object that is difficult to } \\
\text { reposition due to a physical } \\
\text { appearance }\end{array}$ & $\begin{array}{l}\text { Refrigerator, freezer (Family } \\
\text { sized) }\end{array}$ \\
\hline & 5 & $\begin{array}{l}\text { Medium object that is sometime } \\
\text { difficult to reposition }\end{array}$ & $\begin{array}{l}\text { Table, Chair, Freezer, Small } \\
\text { refrigerator, Personal Computer, } \\
\text { Workstation, Office plant }\end{array}$ \\
\hline & 6 & $\begin{array}{l}\text { Small object that is easy to } \\
\text { reposition or detachable }\end{array}$ & $\begin{array}{l}\text { Litter bin, Rug, Portable } \\
\text { Equipment, Fire extinguisher }\end{array}$ \\
\hline \multirow[t]{3}{*}{$\begin{array}{l}\text { Transient } \\
\text { Objects }\end{array}$} & 7 & $\begin{array}{l}\text { Unintentional or accidental } \\
\text { objects }\end{array}$ & Wet floor, Litters \\
\hline & 8 & Objects created by schedules & Cleaning area \\
\hline & 9 & Self-moving objects & $\begin{array}{l}\text { People, Pet Robots, Autonomous } \\
\text { System }\end{array}$ \\
\hline
\end{tabular}

\section{Findings}

Analysis of findings classified into two sections showed that visually impaired people experience a lot of problems navigating inside the buildings and public spaces. Section 4.1 describes be- 
haviors, strategies used, and challenges experienced by visually impaired people when walking inside buildings and public spaces full of unfamiliar features. Section 4.2 describes the framework validation task where all of the factors from the preliminary study were validated with statistical analysis provided, and finally included into the finalized version of SRF.

\subsection{Problems and Challenges in Indoor Navigation by Blind People}

There are four types of space whose difficulty in navigating need to be considered separately: wide-open area, hallway, small room, and large room. $78 \%$ of participants said they are not confident in navigating through wide-open areas, hallways, and large rooms, as it is too difficult to navigate independently. Most participants got lost usually while just standing or navigating through the wide-open areas, where there are not many landmarks they can use to help them detect their orientation. These problems also happened when walking through the hallways as some are too wide, and some obstacles cannot be detected by the white cane (e.g., wallmounted furniture and fire extinguisher), and sometimes can harm people encountering them. Nevertheless, walking inside small rooms is easier as $45 \%$ of the participants said they can sense and feel the landmarks, walking inside large rooms is, on the other hand, difficult (said by $87 \%$ of the participants) due to the lack of accessibility information, inclusive design, and non-standard furniture and equipment.

Although a white cane is commonly said to be used as the first-choice "helper" by sighted people, visually impaired people have experienced the challenges when walking inside unfamiliar space, where a common tool like the white cane cannot help them navigate independently, and neither can a guide dog. For example, a slippery floor caused by water or fabric dropped on the floor, as well as body-level and head-level obstacles they run into inside the spaces. The results revealed that $74 \%$ of visually impaired people cannot navigate in the unfamiliar spaces at the first attempt even if accompanied with the white cane. As a result, they need to be accompanied by sighted guides, in order to learn and familiarize themselves with the spaces before independent navigation with a white cane or other assistance.

Regarding distance estimation, sighted people think counting footsteps is an appropriate strategy when walking inside both familiar and unfamiliar spaces, while people with visual impairment do not know the features inside the spaces. However, this strategy may take a lot of mental effort, and some people can be easily distracted, especially those born blind who have never seen the world, if walking into an obstacle (e.g., furniture and landmarks) or people, especially in spaces full of unfamiliar features and full of crowds and noise. However, $50 \%$ of visually impaired people rely on their sense and feeling, focusing on the use of environment information to estimate distance, e.g., smell, light, floor texture, and landmarks, while a minority of people, who are confident in navigation independently, employ a combination of strategies for navigation instead of using one particular strategy. For example, sense and feeling and counting footsteps or timing strategies.

In terms of wayfinding and orientation when visiting unfamiliar spaces, most navigation problems in unfamiliar spaces revolve around three challenges: finding their current location, finding a path to a destination, and finding and maintaining orientation. Since they are unfamiliar with the spaces, visually impaired people are not able to use any source of information in the areas, e.g., landmarks on which the sighted usually rely, in order to estimate their location and orientation. The findings revealed that they first need a sighted guide in order to learn and familiarize themselves with the spaces, rather than use landmarks to find location and orientation. Once they have learned the space, they will use three simultaneous clues: floor texture, environment cues, and landmarks, which are perceived by their sense and feeling. One participant said that to find his orientation while navigating in his home, he has mentally drawn an image of the relationships between each landmark and other landmarks or environment cues.

Obstacles and barriers are something that people with visual impairment face every day. 
Most participants reported by hitting an obstacle it can cause them to lose their balance and orientation. The findings suggested that noise is the most impact factor they face, while silence is the least. In a wide-open area, too much noise creates a lot of distraction, which results in a loss of orientation. This situation usually happens when the space is full of crowds (e.g., malls). On the other hand, a too quiet space tends to panic visually impaired people. Consequently, people may think that the direction they are walking in is wrong and can cause a serious injury, for example walking inside a building where some area is being renovated and warning notices are not provided or usable for people with visual impairment. Nonetheless, the study has found that light is useful and important to partially sighted people. People have used the light as a 'helper' to detect distance and orientation while navigating inside buildings. However, in some areas, if the light is too bright and shines in the eye, it causes temporary blindness.

\subsection{Validation of the Spatial Representation Framework}

In this section, both groups (visually impaired people, and sighted people) were asked to rate the importance of factors to be included in the framework. 23 factors were suggested regarding information necessary to navigate unfamiliar indoor spaces by people with visual impairment. The responses were based on a five point Likert scale, where 1 is Not Important, 2 is Not Very Important, 3 is Somewhat Important, 4 is Important, and 5 is Very important. SPSS software was used to analyze this data. The hypothesis was tested for each factor using a one-sample t-test with a test value of 3 . The proposed factor is considered to be included in the framework as long as its mean value $\geq 3$. Factors are considered to be statistically significant if the $p$-value $<0.05 / 5=0.01$, where 5 is the number of levels categorized in the proposed framework and used to decreasing the chance of Type I error with multiple analysis [24], shown in Table 3.

The Table 3 shows the results of the analysis from the perspectives of people with visual impairment, and sighted people. From the point of view of visually impaired people, it is clear that all of the proposed factors were considered to have impact on indoor navigation by people with visual impairment as the mean value of each factor is more than 3 . Most of the proposed factors were found to be statistically significant as their $p$-values are less than the significant level, except for Wi-Fi coverage and noise.

Sighted people also thought that most of the factors would impact on indoor navigation, except for lighting because most people with visual impairment lack light perception and light is therefore not very useful. Five factors were not found to be statistically significant: lighting, building profile, event and exhibition, weather, and reception.

Table 4 compares the two population means of the visually impaired people and sighted people. In general, both groups of participants agreed with most factors, as different means are shown to be not significant, except for the following factors: floor number, entrance and exit, emergency exit, lighting, tactile pavement, and noise. The means of these six factors from the two samples were still $\geq 4$ (Important), except for the lighting factor whose means were 3.63 ( $\geq 3$ Somewhat Important) for visually impaired people, and 2.60 ( $\geq 2$ Not very Important) for sighted people.

The reliability of these survey results was determined using Cronbach's Alpha. Cronbach's alpha returned a value of 0.802 for the survey from people with visual impairment, and 0.895 for the survey from sighted people. These values indicate that the reliability coefficient for the results is sufficient [25].

\section{Discussion of the Findings}

The framework validation was undertaken by both groups of people: visually impaired people, and sighted people shown in the previous section. The findings showed that one particular factor needs to be considered as a main factor in the spatial representation framework. In the 
Table 3: Results of t-test between visually impaired people (One sample t-test) and sighted people (Wilcoxon signed-rank test)

\begin{tabular}{|c|c|c|c|c|}
\hline \multirow[t]{2}{*}{ Factors } & \multicolumn{2}{|c|}{ Visually Impaired } & \multicolumn{2}{|c|}{ Sighted } \\
\hline & Mean & Sig. (2-tailed) & Mean & Sig. (2-tailed) \\
\hline \multicolumn{5}{|l|}{ Structural } \\
\hline Floor Layout & 3.67 & 0.005 & 4.27 & 0.001 \\
\hline Floor Number & 4.10 & $<.001$ & 4.67 & $<.001$ \\
\hline Room Number & 4.17 & $<.001$ & 4.67 & $<.001$ \\
\hline Toilet and Bathroom & 4.30 & $<.001$ & 4.47 & 0.001 \\
\hline Entrance and Exit & 4.40 & $<.001$ & 4.73 & $<.001$ \\
\hline Emergency Exit & 4.13 & $<.001$ & 4.60 & 0.001 \\
\hline \multicolumn{5}{|l|}{ Objects } \\
\hline Doors & 4.63 & $<.001$ & 4.60 & 0.001 \\
\hline Stairs & 4.23 & $<.001$ & 4.33 & 0.001 \\
\hline Lifts & 4.17 & $<.001$ & 4.27 & 0.001 \\
\hline Steps, Drop-offs, and Curbs & 4.20 & $<.001$ & 4.53 & $<.001$ \\
\hline Escalators & 4.00 & $<.001$ & 4.07 & 0.001 \\
\hline Furniture & 4.10 & $<.001$ & 3.93 & 0.01 \\
\hline People & 4.00 & $<.001$ & 3.67 & 0.02 \\
\hline \multicolumn{5}{|l|}{ Sensors } \\
\hline Lighting & 3.63 & 0.008 & 2.60 & $0.214^{*}$ \\
\hline Wi-Fi Coverage & 3.10 & $0.698^{*}$ & 3.07 & $0.902^{*}$ \\
\hline \multicolumn{5}{|l|}{ Path } \\
\hline Walkable area & 4.20 & $<.001$ & 4.13 & 0.007 \\
\hline Tactile Pavement & 3.93 & $<.001$ & 4.60 & $<.001$ \\
\hline \multicolumn{5}{|l|}{ Information } \\
\hline Building Profile & 3.70 & 0.003 & 3.93 & $0.017^{*}$ \\
\hline Event and Exhibition & 3.77 & $<.001$ & 3.47 & $0.053^{*}$ \\
\hline Dangerous area & 4.20 & $<.001$ & 4.60 & 0.001 \\
\hline Weather & 3.67 & 0.004 & 2.93 & $0.665^{*}$ \\
\hline Reception & 3.87 & $<.001$ & 3.80 & $0.073^{*}$ \\
\hline Noise & 3.17 & $0.531^{*}$ & 4.07 & 0.004 \\
\hline
\end{tabular}

${ }^{*}$ The population mean would not be statistically significantly different

following sections, the findings from both tasks: indoor navigation problems and framework validation are discussed.

\subsection{Problems and Challenges in Indoor Navigation by Blind People}

This task has shown that visually impaired people first use sighted guides as helpers when visiting unfamiliar spaces in order to learn and familiarize themselves with navigational cues, e.g. landmarks and hazards. Five additional factors were revealed that provide them with confidence and safety while navigating inside buildings and public spaces, as outlined below.

- Navigational Cues: This factor contains markers and information about the objects, e.g. edges and corners, areas, e.g. intersection, especially transition spaces, e.g. stairs: tread width, riser height, and depth width. This information is important and can be 
Table 4: Equality of variances and equality of means between visually impaired people and sighted people

\begin{tabular}{|c|c|c|c|c|}
\hline \multirow[t]{2}{*}{ Factors } & \multicolumn{2}{|c|}{ Equality of Variances } & \multicolumn{2}{|c|}{ Equality of Means } \\
\hline & $\mathbf{F}$ & Sig. & $\begin{array}{c}\text { Sig. } \\
\text { (2-tailed) }\end{array}$ & $\begin{array}{c}\text { Mean } \\
\text { Difference }\end{array}$ \\
\hline \multicolumn{5}{|l|}{ Structural } \\
\hline Floor Layout & 1.894 & 0.176 & 0.084 & -0.6 \\
\hline Floor Number & 0.569 & 0.455 & $0.044^{*}$ & -0.5667 \\
\hline Room Number & 0.505 & 0.481 & 0.054 & -0.5 \\
\hline Toilet and Bathroom & 1.732 & 0.195 & 0.42 & -0.1667 \\
\hline Entrance and Exit & 3.666 & 0.062 & $0.035^{*}$ & -0.3333 \\
\hline Emergency Exit & 0.125 & 0.725 & $0.041^{*}$ & -0.4667 \\
\hline \multicolumn{5}{|l|}{ Objects } \\
\hline Doors & 1.116 & 0.294 & 0.846 & 0.0333 \\
\hline Stairs & 0.02 & 0.888 & 0.666 & -0.1 \\
\hline Lifts & 0.864 & 0.358 & 0.57 & -0.1 \\
\hline Steps, Drop-offs, and Curbs & 0.648 & 0.425 & 0.057 & -0.3333 \\
\hline Escalators & 0.732 & 0.397 & 0.774 & -0.0667 \\
\hline Furniture & 0.334 & 0.566 & 0.481 & 0.1667 \\
\hline People & 0.652 & 0.424 & 0.251 & 0.3334 \\
\hline \multicolumn{5}{|l|}{ Sensors } \\
\hline Lighting & 2.003 & 0.164 & $0.017^{*}$ & 1.0333 \\
\hline Wi-Fi Coverage & 0.722 & 0.4 & 0.94 & 0.0333 \\
\hline \multicolumn{5}{|l|}{ Path } \\
\hline Walkable area & 0.861 & 0.359 & 0.797 & 0.0667 \\
\hline Tactile Pavement & 1.844 & 0.182 & $0.037^{*}$ & -0.6667 \\
\hline \multicolumn{5}{|l|}{ Information } \\
\hline Building Profile & 0.149 & 0.701 & 0.526 & -0.2333 \\
\hline Event and Exhibition & 0.417 & 0.522 & 0.221 & 0.3 \\
\hline Dangerous area & 0.104 & 0.749 & 0.114 & -0.4 \\
\hline Weather & 0.213 & 0.647 & 0.055 & 0.7333 \\
\hline Reception & 2.661 & 0.11 & 0.845 & 0.0667 \\
\hline Noise & 4.474 & 0.04 & $0.017^{*}$ & -0.9 \\
\hline
\end{tabular}

* there is significant difference between the means of these two samples

used as a navigational cue to help people find their way more easily when navigating inside buildings full of unfamiliar features.

- Warning This factor contains warning markers and information about hazards, e.g. sharp edges, stairs and escalators, slippery surfaces, holes, drop-offs, and especially glass doors and automatic sliding doors. This component is useful in providing free mobility when navigating indoors.

- Profile: This factor acts as metadata containing a description of the areas and objects placed or installed inside the buildings, including information about their physical dimension, size, wall type, etc. This component also includes general information about the building, e.g. building profile, pre-visit information, etc. 
- State: This is a sub-factor of the profile component and contains information about the current state of the objects, especially transition spaces, e.g. doors, elevators, escalators, and travellators. For example, door (open, closed), escalator (going up, going down), or lift (going up, going down, current floor).

- External: This factor contains sensory information that potentially impacts indoor navigation such as light from windows, noise from rain, car horn, or construction outside the building. This component is of use to people with visual impairment, especially those who are partially sighted that use light to detect orientation in the wayfinding process.

\subsection{Validation of the Spatial Representation Framework}

In the framework validation task, all the factors from the preliminary study [22] were included in the SRF, and most were found to be statistically significant, as shown in Table 3. Seven factors were found not to be statistically significant by the visually impaired, or by sighted people, or both. These included, noise found by visually impaired people, lighting, building profile, event and exhibition, weather and reception factors found by sighted people, while Wi-Fi coverage was found by both.

All the not-significant factors found by each group complement each other, except Wi- Fi coverage that was found not to be statistically significant by both teams. However, although Wi$\mathrm{Fi}$ is not statistically significant, this factor is useful for the construction of an indoor navigation system and may be of use in future development, and so is included in the framework as part of the sensor factor.

The study has shown that all the proposed factors were agreed on by both groups of people, except the lighting factor that sighted people thought was not useful. For this factor, all the partially sighted participants said that lighting is most important since they can see use it to identify direction and some people have used it as a reference point. In addition, some visually impaired people still have light perception, and so have used it to detect direction. Thus, the lighting factor must be considered part of the framework.

\section{Conclusion}

Outdoors, visually impaired people can sense and use the environment cues from the white cane, while inside public spaces has its own set of difficulties and many environmental cues cannot be used. Some technologies help these people to have freedom in navigation when they need additional information (obstacles, barriers, and accessibility), which led to this study for the promotion of navigation by visually impaired people. To investigate what additional information can promote the indoor navigation, information and feedback from visually impaired people is important. Therefore, 45 participants (30 visually impaired and 15 sighed people) were recruited and interviewed or completed questionnaires regarding indoor navigation problems.

The findings revealed that navigating inside buildings and public spaces full of unfamiliar features is too difficult to attempt the first time for a number of reasons, reducing the confidence in independent navigation. Navigation inside buildings by visually impaired people is a challenge as it takes a long time to become familiar with spaces which leads to the need for sighted people's assistance but is a problem regarding distance estimation, and instruction to the destination. Many difficulties are experienced by visually impaired people while inside the public spaces full of unfamiliar features, for example obstacles, barriers and accessibility information, that have made them unable to navigate safely. To overcome that, the use of indoor landmarks was found to be significantly useful for visually impaired people. Not only landmarks have been used, the environment cues (e.g., light, smell, and noise) are also used in wayfinding and mental map construction processes. 
Framework validation results showed that visually impaired and sighted people agreed with all the proposed factors included in the finalized version of SRF, except for seven factors: Wi-Fi coverage and noise (by visually impaired people), and lighting, Wi-Fi coverage, building profile, event/ exhibition, weather, and reception (by sighted people). However, in order to learn and familiarize themselves with spaces, five additional factors were revealed that provide them with confidence and safety while navigating inside buildings and public spaces, such as navigational cues, warning, profile, state, and external.

The SRF was validated in the field study, and presented as a conceptual framework used to support indoor navigation by people with visual impairment in places full of unfamiliar features. The framework consists of eleven components organized into five layers: structural, objects, sensor, path, and wayfinding layer. A scaling method was defined for object classification to characterize their movability: 0-3 for fixed, 4-6 for rearrangeable, and 7-9 for transient objects. As indoor spatial information provided, many applications can be extended to provide a range of indoor-based applications by using the SRF to represent indoor spaces. Example applications are: indoor navigation by people with disabilities, robots and autonomous systems, security and surveillance, and context and spatial awareness.

\section{A Supplementary Material}

The preliminary study related to this article can be accessed at https://doi.org/10.1109/iSociety.2016.7854184

\section{References}

[1] WHO Media Centre. Visual impairment and blindness. http://www . who. int/mediacentre/ factsheets/fs282/en/. [Online; accessed 16-May-2016]. 2014.

[2] Ki-Joune Li and Jiyeong Lee. "Indoor spatial awareness initiative and standard for indoor spatial data". In: Proceedings of IROS 2010 Workshop on Standardization for Service Robot. Vol. 18. 2010.

[3] Limin Zeng. "A Survey: Outdoor Mobility Experiences by the Visually Impaired". In: Mensch und Computer 2015-Workshopband (2015).

[4] Tommy Edison. How Blind People Cross The Street Alone. https ://youtu . be/48DqdwzftnQ. [Online; accessed 14-March-2016]. 2011.

[5] Michele A Williams, Amy Hurst, and Shaun K Kane. "Pray before you step out: describing personal and situational blind navigation behaviors". In: Proceedings of the 15th International ACM SIGACCESS Conference on Computers and Accessibility. ACM. 2013, p. 28.

[6] Zaira Cattaneo and Tomaso Vecchi. Blind vision: the neuroscience of visual impairment. MIT Press, 2011.

[7] Aura Ganz et al. "PERCEPT indoor navigation system for the blind and visually impaired: architecture and experimentation". In: International journal of telemedicine and applications 2012 (2012), p. 19.

[8] Lorenzo Picinali et al. "Exploration of architectural spaces by blind people using auditory virtual reality for the construction of spatial knowledge". In: International Journal of Human-Computer Studies 72.4 (2014), pp. 393-407.

[9] Vladimir Kulyukin et al. "RFID in robot-assisted indoor navigation for the visually impaired". In: Proceedings of 2004 IEEE/RSJ International Conference on Intelligent Robots and Systems, 2004.(IROS 2004). Vol. 2. IEEE. 2004, pp. 1979-1984. 
[10] Guidedogs.org.uk. Are dogs allowed everywhere? - All Access Areas / Guide Dogs. https: //goo.gl/gxQp39. [Online; accessed 5-May-2016]. 2016.

[11] Guidedogs.org.au. Frequently Asked Questions - GuideDogs SA/NT. https : //www . guidedogs . org . au / frequently-asked-questions. [Online; accessed 5-May-2016]. 2016 .

[12] Martin Goldberg, Zhigang Zhu, and Zhanyang Zhang. "How do We Aid Visually Impaired People Safely Manage Unfamiliar Environments?" In: (2018).

[13] Roberto Manduchi and Sri Kurniawan. "Mobility-related accidents experienced by people with visual impairment”. In: AER Journal: Research and Practice in Visual Impairment and Blindness 4.2 (2011), pp. 44-54.

[14] Fazli Subhan et al. "Indoor positioning in bluetooth networks using fingerprinting and lateration approach". In: Information Science and Applications (ICISA), 2011 International Conference on. IEEE. 2011, pp. 1-9.

[15] Deepak Vasisht, Swarun Kumar, and Dina Katabi. "Decimeter-Level Localization with a Single WiFi Access Point". In: 13th USENIX Symposium on Networked Systems Design and Implementation (NSDI 16). 2016, pp. 165-178.

[16] Mei Miao, Martin Spindler, and Gerhard Weber. Requirements of indoor navigation system from blind users. Springer, 2011.

[17] Konstantinos Papadopoulos et al. "User requirements regarding information included in audio-tactile maps for individuals with blindness". In: International Conference on Computers Helping People with Special Needs. Springer. 2016, pp. 168-175.

[18] Simon Ungar, Mark Blades, and Christopher Spencer. "Can a tactile map facilitate learning of related information by blind and visually impaired people? a test of the conjoint retention hypothesis". In: Proceedings of Thinking with Diagrams 98 (2000).

[19] Simon Ungar, Andrew Simpson, and Mark Blades. "Strategies for organising information while learning a map by blind and sighted people". In: Uiversidad Nacional de Educacion a Distancia (2004).

[20] Laura B Martins, Francisco J Lima, et al. "Analysis of wayfinding strategies of blind people using tactile maps". In: Procedia Manufacturing 3 (2015), pp. 6020-6027.

[21] Victor R Schinazi, Tyler Thrash, and Daniel-Robert Chebat. "Spatial navigation by congenitally blind individuals". In: Wiley Interdisciplinary Reviews: Cognitive Science 7.1 (2016), pp. 37-58.

[22] Watthanasak Jeamwatthanachai, Mike Wald, and Gary Wills. "Map data representation for indoor navigation a design framework towards a construction of indoor map". In: 2016 International Conference on Information Society (i-Society). IEEE. 2016, pp. 91-96.

[23] J Lee et al. OGC@ IndoorGML. 2014.

[24] C Bonferroni. "Teoria statistica delle classi e calcolo delle probabilita". In: Pubblicazioni del $R$ Istituto Superiore di Scienze Economiche e Commericiali di Firenze 8 (1936), pp. 362.

[25] Rosemary R Gliem and Joseph A Gliem. "Calculating, interpreting, and reporting Cronbach's alpha reliability coefficient for Likert-type scales". In: Midwest Research-to-Practice Conference in Adult, Continuing, and Community Education. 2003. 


\section{Biography}

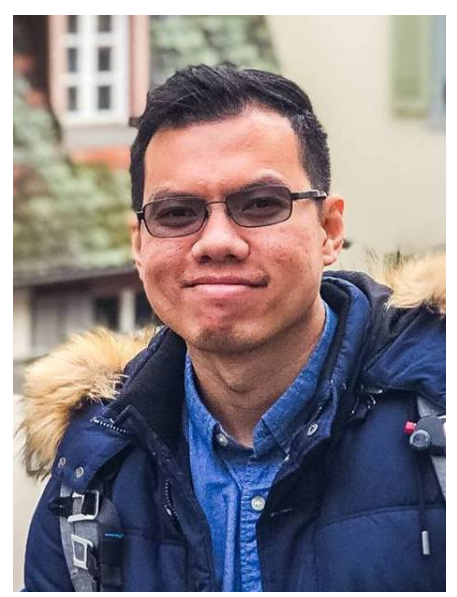

Watthanasak Jeamwatthanachai, also known as Hall. Hall is a researcher at the National Electronics and Computer Technology Center (NECTEC). He is also a PhD candidate in the Cyber Physical System (CPS) research group. He has been researching on the topic of Human-Computer Interaction and Informatics, specializing in Spatial Representation for better indoor navigation by people with visual impairment. His research is focusing on how to create maps that can be visualized in 3D geography with full detail of information that meets the need of people with sight loss. The motivation is to help people with sight loss to have a freedom in navigation indoors. He is also interested in expanding and utilizing the 3D map into other research areas of autonomous systems, indoor position systems, new enabling technologies and other indoor-based systems. 